\title{
Vulnerabilidade socioambiental: uma análise dos indicadores na cidade de Natal/RN
}

Indicadores podem ser compreendidos como uma medida que busca sintetizar informações relevantes de um dado fenômeno, analisando seu comportamento ao longo de um espaço temporal. Quando utilizados para análise da vulnerabilidade socioambiental o uso dessa ferramenta se torna fundamental, pois permite a identificação de bairros vulneráveis e facilita seu monitoramento temporal, viabilizando o acompanhamento das variáveis analisadas. Neste sentido, este artigo tem como objetivo analisar a vulnerabilidade socioambiental da cidade de Natal- RN, a partir de um conjunto de indicadores que enfatizam as questões sociais e ambientais e que caracterizam o cenário urbano brasileiro. Para tanto, realizou-se um estudo exploratório e descritivo, por meio da pesquisa bibliográfica e documental. Os resultados apontam que o nível de vulnerabilidade socioambiental para a cidade de Natal foi de 0,4709, classificado como 'Alto'. Esse resultado é considerado insatisfatório e preocupante, pois coloca a cidade frente a muitas problemáticas que demandam urgência na sua resolução, como forma de garantir condições mínimas de qualidade de vida aos seus citadinos. No entanto, é importante salientar a importância de analisar a cidade com um olhar mais direcionado para cada tema e cada indicador analisado e identificar quais deles necessitam de mais atenção para sanar as problemáticas que os envolvem.

Palavras-chave: Indicadores; Vulnerabilidade; Urbano.

\section{Social-environmental vulnerability: an analysis of the indicators in the city of Natal/RN}

\begin{abstract}
Indicators can be understood as a measure that seeks to synthesize relevant information from a given phenomenon, analyzing its behavior over a temporal space. When used to analyze socio-environmental vulnerability, the use of this tool becomes fundamental, since it allows the identification of vulnerable neighborhoods and facilitates their temporal monitoring, making possible the monitoring of the analyzed variables. In this sense, this article aims to analyze the socioenvironmental vulnerability of the city of Natal-RN, based on a set of indicators that emphasize social and environmental issues and characterize the Brazilian urban scenario. For that, an exploratory and descriptive study was carried out, through bibliographical and documentary research. The results indicate that the level of socio-environmental vulnerability for the city of Natal was 0.4709 , classified as 'High'. This result is considered unsatisfactory and worrying because it puts the city facing many problems that require urgency in its resolution, in order to guarantee minimum conditions of quality of life for its citizens. However, it is important to stress the importance of analyzing the city with a more targeted look at each theme and each indicator analyzed and identifying which ones need more attention to mitigate the issues that involve them.
\end{abstract}

Keywords: Indicators; Vulnerability; Urban.

Topic: Planejamento, Gestão e Políticas Públicas Ambientais

Reviewed anonymously in the process of blind peer.
Received: 02/12/2018

Approved: 26/01/2019
Ana Cecília Feitosa de Vasconcelos (iD)

Universidade Federal de Campina Grande, Brasil

http://lattes.cnpq.br/6492366302935662

http://orcid.org/0000-0002-7848-4602

acvasconcelos@gmail.com

Eliza Maria Xavier Freire

Universidade Federal do Rio Grande do Norte, Brasil

http://lattes.cnpq.br/6388455734228621

http://orcid.org/0000-0001-9486-6347

elizajuju1000@gmail.com

Gesinaldo Ataíde Cândido (iD

Universidade Federal de Campina Grande, Brasil

http://lattes.cnpq.br/2771934125977891

http://orcid.org/0000-0002-3112-0254

gacandido@uol.com.br

\section{Referencing this:}

VASCONCELOS, A. C. F.; FREIRE, E. M. X.; CÂNDIDO, G. A..

Vulnerabilidade socioambiental: uma análise dos indicadores na cidade de Natal/RN. Revista Ibero Americana de Ciências Ambientais, v.10, n.1, p.323-339, 2019. DOI: http://doi.org/10.6008/CBPC2179$\underline{6858.2019 .001 .0027}$ 


\section{INTRODUÇÃO}

Indicadores podem ser compreendidos como uma medida que busca sintetizar informações relevantes de um dado fenômeno, analisando seu comportamento ao longo de um intervalo temporal. Por serem percebidos como uma ferramenta importante no debate que envolve as questões de interesse público, quando bem elaborados, sua utilização pode proporcionar conclusões analíticas ou políticas de forma mais simples. É neste contexto que se entende que para a utilização de indicadores, é necessário o embasamento teórico acerca do fenômeno estudado, neste caso específico, a vulnerabilidade socioambiental, bem como o conhecimento de técnicas que viabilizem a sua execução e da contribuição para uma melhor compreensão do fenômeno que o sistema de indicadores envolve.

Para este estudo, a vulnerabilidade socioambiental é o elemento a ser analisado e, portanto, é preciso compreender sua definição. Para Cutter (2011) vulnerabilidade corresponde ao "potencial para a perda". Para esta autora, a vulnerabilidade inclui tanto os "elementos de exposição ao risco" como os "fatores de propensão às circunstâncias que aumentam ou reduzem as capacidades da população, das infraestruturas ou dos sistemas físicos para responder e se recuperar de ameaças ambientais" (CUTTER, 2011).

É nesse sentido que os problemas advindos da poluição e degradação do meio, da crise dos recursos naturais energéticos e alimentares, das mudanças climáticas que atingem todo o planeta, se tornam mais impactantes em áreas periféricas, que além de acometidos pela pobreza, sequer tem os seus direitos civis atendidos. São nessas áreas periféricas que o poder público, em geral, está ausente e onde existe uma deficiência de estrutura capaz de oferecer à população oportunidades dignas de serviços, trabalho e lazer.

Nesta perspectiva, Kowarick (2000) expõe que não só a relação natureza e sociedade gera a vulnerabilidade, mas afirma que existe muita vulnerabilidade em relação a direitos básicos, na medida em que não só os sistemas públicos de proteção social foram sempre restritos e precários, como também, em anos recentes, houve desmonte de serviços e novas regulamentações que se traduziram em perda de direitos adquiridos.

Embasada nesse entendimento é que se reconhece que o estudo da vulnerabilidade envolve uma discussão ampla e relevante por ter um caráter multidisciplinar e indica que a suscetibilidade das pessoas a problemas e perdas estão, principalmente, relacionadas ao conjunto das profundas transformações sociais, econômicas e ambientais que afetam, pelo mundo inteiro, as pessoas ou grupos de pessoas (KOWARICK, 2009).

Ademais, é preciso a compreensão de que a definição de vulnerabilidade socioambiental deve envolver uma percepção mais integrada das condições de vida de uma dada população. Deve-se olhar e perceber que os impactos advindos dos desastres naturais reconfiguram os cenários urbanos e impactam a forma e condição de vida das pessoas, mas também, que o contexto de construção da sociedade e do processo de expansão urbana nas cidades brasileiras, faz com que uma parte da população desconheça seus 
direitos e experimentem de forma intensa uma sobreposição de desigualdades sociais: pobreza, segregação espacial, ausência de conforto urbano e, principalmente, os direitos à cidadania.

De acordo com o documento final da Conferência Mundial para a Redução de Desastres em Kobe (UN, 2005) é latente a necessidade de se desenvolver indicadores de risco e vulnerabilidade nos níveis nacional e subnacional como forma de permitir aos tomadores de decisão um melhor diagnóstico das situações de risco e vulnerabilidade.

É nesse sentido que nas pesquisas sobre a vulnerabilidade socioambiental urbana no Brasil, destacase a importância de estudar as cidades com um olhar mais direcionado para os problemas sociais, que explicitam um nível mais baixo de qualidade de vida, decorrente, em geral, dos fenômenos de conurbação e periferização, advindos do processo de adensamento populacional. Tais fenômenos levam uma parcela da população a ocuparem novas áreas, modificando o uso do solo, se tornando invisíveis aos olhos do poder público e, consequentemente, compondo um quadro de vulnerabilidade socioambiental.

Estudar a vulnerabilidade socioambiental nas cidades brasileiras exige uma perspectiva mais ampla. É preciso compreender que o processo de vulnerabilidade no Brasil não decorre dos desastres naturais, mas das questões sociais que acometem as pessoas que vivem nos centros urbanos. Por esta compreensão é preciso que se tome como base as questões que envolvem o processo histórico e cultural de expansão urbana nas cidades e se compreenda todas as dificuldades sociais e econômicas a que muitas pessoas são submetidas nas cidades. Nesse sentido, neste estudo optou-se por seguir alguns autores que enfatizam em seus estudos as problemáticas que acometem as cidades. Dentre eles, pode-se citar: Herculano (2000), Sposati (2000), Alves (2006), Kowarick (2009), Souza (2009), Maricato (2014), Gehl (2015), Rogers (2015), Rolnik (2015) e outros autores que estudam as problemáticas urbanas como suporte a estes autores: Braga et al. (2002), Nahas (2002), Rossetto (2003), Machado (2004), Braga (2006), Morato (2008), Figueiredo (2008), Ribeiro (2008), Roggero (2009), Florissi (2009), Veiga (2010), Jacobs (2011), Pessoa (2012), Araújo (2013), Maior (2014), Roggero (2015), Martins et al. (2015), Pereira et al. (2016), Gomes et al. (2017).

Com base nos apontamentos até aqui realizados, o presente estudo adota como recorte espacial a cidade de Natal, capital do Rio Grande do Norte, uma vez que possui uma dinâmica socioambiental urbana complexa, decorrente das suas características naturais. A referida capital tem sido alvo de muitos investimentos, tanto no âmbito público quanto no privado, ao passo que percebe-se outras áreas que, em decorrência do crescimento desordenado, exigem uma maior demanda por serviços de infraestrutura e moradia. Deste modo, a escolha de Natal está relacionada ao seu processo de expansão urbana, bem como por sua importância econômica e política que possui, por ser capital do estado.

A partir destas considerações, este artigo tem como objetivo analisar a vulnerabilidade socioambiental da cidade de Natal/RN, a partir de um conjunto de indicadores que enfatiza as questões sociais e ambientais que caracterizam o cenário urbano brasileiro. Em termos metodológicos este estudo se classifica como sendo exploratório e descritivo. Neste caso específico, pela necessidade de descrição de uma realidade revelada através do cálculo do índice de vulnerabilidade socioambiental urbano da cidade de Natal/RN. As técnicas de pesquisa adotadas foram a pesquisa bibliográfica, como forma de obter 
embasamento teórico no que se refere aos conceitos e abordagens sobre as temáticas; a pesquisa documental para levantar dados e informações necessárias da cidade, bem como os dados referentes aos indicadores de vulnerabilidade socioambiental escolhidos para a análise dos bairros de Natal. Este artigo apresenta, além destas considerações iniciais que contextualizam a problemática do estudo, a segunda seção que apresenta os procedimentos metodológicos utilizado para o alcance do objetivo e, em seguida a apresentação e análise dos resultados e as considerações finais.

\section{METODOLOGIA}

Dada às características da pesquisa realizada, este estudo se classifica como sendo exploratório e descritivo. Neste caso específico, pela necessidade de descrição de uma realidade revelada através do cálculo do índice de vulnerabilidade socioambiental urbano da cidade brasileiras, o qual foi conduzido sob a forma de estudo de caso na cidade de Natal/RN.

As técnicas de pesquisa adotadas foram a pesquisa bibliográfica, como forma de obter embasamento teórico no que se refere aos conceitos e abordagens sobre as temáticas; a pesquisa documental para levantar dados e informações necessárias da cidade, bem como os dados referentes aos indicadores de vulnerabilidade socioambiental escolhidos para a análise dos bairros de Natal.

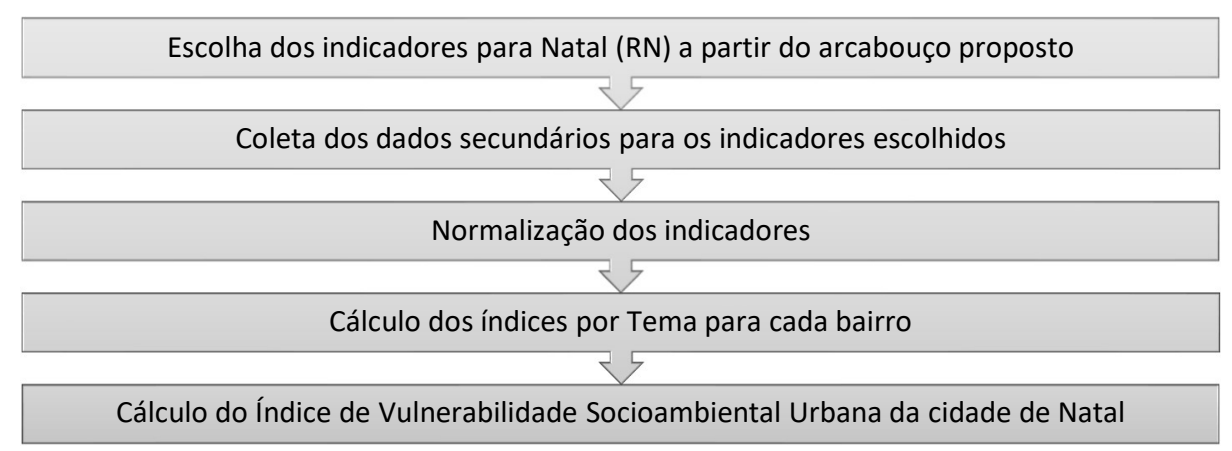

Figura 1: Delineamento esquemático da aplicação do Modelo Operacional.

A partir da explicitação do delineamento metodológico, segue abaixo a explicação e cada uma das etapas como forma de facilitar o entendimento e a sua operacionalização para obtenção do índice de vulnerabilidade socioambiental para a cidade de Natal/RN

\section{Escolha dos indicadores para análise de Natal/RN}

A escolha dos indicadores é realizada em função da disponibilidade dos dados disponíveis no nível de granularidade por bairros. Para tanto, diante do conjunto de 134 indicadores propostos, serão utilizados todos os indicadores que tenham dados disponíveis para os bairros de Natal. É importante destacar que o Tema Governança é constituído por indicadores que são analisados apenas para cidades de forma binária. A existência dos indicadores na cidade analisada será considerada uma situação ideal, devendo-se ser atribuído valor 1,00 (nível de vulnerabilidade muito baixo). A ausência dos indicadores na cidade é considerada uma situação irregular, devendo-se ser atribuído valor 0,00 (nível de vulnerabilidade muito alto). Para a coleta de dados e cálculo dos demais indicadores, deve-se seguir as etapas que estão elencadas abaixo. 
Quadro 2: Indicadores de Vulnerabilidade Socioambiental para cidades brasileiras.

\begin{tabular}{|c|c|c|}
\hline Dimensão & Temas & Indicadores \\
\hline \multirow{5}{*}{ Social } & Saúde & $\begin{array}{l}\text { Oferta de serviços básicos de saúde; Profissionais de Saúde; Taxa de estabelecimento de saúde; } \\
\text { Taxa de estabelecimentos de saúde; Taxa de leitos hospitalares/SUS por } 1000 \text { habitantes; Unidades } \\
\text { de média complexidade; Taxa de unidades de atenção básica; Atendimento odontológicos do SUS; } \\
\text { Imunização contra doenças infecciosas infantis; Taxa de mortalidade infantil; Esperança de vida ao } \\
\text { nascer; Taxa de fertilidade; Quant. de adolescentes grávidas; Quant. de abortos; Quant. de casos } \\
\text { de dengue; Quant. de casos de zika; Quant. de casos de chicungunya. }\end{array}$ \\
\hline & $\begin{array}{l}\text { Educação } \\
\text { Cultura }\end{array}$ & $\begin{array}{l}\text { Taxa de Alfabetização; Taxa de Escolarização; Taxa de escolarização líquida no Ensino Médio; Taxa } \\
\text { de escolarização líquida no Ensino Fundamental; Proporção de jovens de } 15 \text { a } 17 \text { anos sem ensino } \\
\text { fundamental completo; Quant. de escolas de ensino fundamental e médio na proximidade; } \\
\text { Quantitativo de matrículas escolares; Pessoas consideradas potencialmente ativa (15-59 anos) que } \\
\text { não sabem ler e escrever; População em idade escolar; Percentual de professores secundários; Taxa } \\
\text { de distorção idade-série; Acesso a computador em casa; Acesso público à internet; Quant. de } \\
\text { museu na proximidade; Quant. de biblioteca na proximidade; Quant. de teatro na proximidade; } \\
\text { Número de estádios e ginásios poliesportivos (ou equipamentos desportivos). }\end{array}$ \\
\hline & Trabalho e renda & $\begin{array}{l}\text { Índice de Gini; Razão rendimento masculino/feminino; Rendimento mensal domiciliar per capita } \\
\text { urbano; Rendimento familiar per capita (\% até } 1 / 2 \mathrm{SM} \text { ); \% de famílias com rendimento de } 10 \text { a } 20 \\
\text { SM; \% de responsáveis por domicílio particular permanente com rendimento mensal de até } 2 \mathrm{SM} \text {; } \\
\% \text { de famílias chefiadas por pessoas jovens; \% de famílias chefiadas por pessoas idosas; População } \\
\text { (urbana) com rendimento mensal domiciliar per capita nominal de até } 1 / 4 \text { salário mínimo; Famílias } \\
\text { atendidas por transferências de benefícios sociais; \% de mulheres jovens responsáveis pelo } \\
\text { domicílio; \% de mulheres idosas responsáveis pelo domicílio; Quant. de famílias monoparentais } \\
\text { com chefia feminina ("mães solteiras"); Quant. de pessoas ocupadas nas empresas do setor } \\
\text { informal; Taxa de Ocupação; Taxa de desemprego; Taxa de Formalidade da Ocupação; Quantitativo } \\
\text { de indústrias na cidade; Quantitativo de empresas com incentivos fiscais; População urbana em } \\
\text { extrema pobreza. }\end{array}$ \\
\hline & Moradia & $\begin{array}{l}\text { Adequação de moradia; Quant. de pessoas que moram em casa própria; Quant. de assentamentos } \\
\text { subnormais na cidade; População em aglomerados subnormais; Taxa de casas localizadas próximas } \\
\text { à córregos e/ou em ambientes sujeitos à inundação; Taxa de casas localizadas em áreas de } \\
\text { acentuada declividade; Domicílio com banheiro - esgotamento sanitário - rede geral; Percentual de } \\
\text { domicílios servidos por rede de esgotamento sanitário; Acesso a esgotamento sanitário; \% de } \\
\text { domicílios particulares permanentes inadequados; \% de domicílios particulares permanentes sem } \\
\text { banheiro; \% de domicílios particulares permanentes com dois ou mais banheiros; Densidade média } \\
\text { de moradores por dormitório; Acesso ao sistema de abastecimento de água; Percentual de } \\
\text { domicílios servidos por rede de água; Domicílios com abastecimento de água - Rede geral, com } \\
\text { banheiro; Acesso a serviço de coleta de lixo doméstico; Percentual de domicílios servidos com } \\
\text { algum tipo de coleta de lixo; Densidade média de moradores de rua; Domicílios com acesso à rede } \\
\text { elétrica; População atendida com frequência de } 2 \text { ou } 3 \text { vezes por semana pelo serviço de coleta de } \\
\text { resíduos; Quant. de conjunto habitacional de interesse social }\end{array}$ \\
\hline & Segurança & $\begin{array}{l}\text { Acesso à justiça; Prevenção de delinquência juvenil; Quant. de assaltos; Pessoas (adultos e } \\
\text { adolescentes) dependentes químicos (álcool, drogas); Taxa de violência nas escolas públicas; } \\
\text { Quantitativo de empresas ou profissionais de segurança privada; Profissionais de segurança pública } \\
\text { por mil habitantes; Taxa de vítimas de acidentes de trânsito; Taxa de mortalidade por homicídios. }\end{array}$ \\
\hline \multirow{3}{*}{ Ambiental } & $\begin{array}{l}\text { Infraestrutura } \\
\text { Urbana }\end{array}$ & $\begin{array}{l}\text { Taxa de urbanização; Taxa de crescimento da população; Densidade demográfica urbana; Quant. } \\
\text { de espaço público para caminhada; Quantitativo de espaços públicos de permanência; Quant. de } \\
\text { praças e/ou parques; Equipamentos públicos; Quant. de ciclovias; Sistema Integrado de Transporte } \\
\text { Coletivo; Média de ônibus por linhas; Abrangência do sistema de transporte coletivo; Qualidade da } \\
\text { Frota de ônibus; Quant. de automóveis; Quant. de Acidentes no trânsito. }\end{array}$ \\
\hline & Governança & $\begin{array}{l}\text { Conselho Municipal de segurança pública; Conselho Municipal do Patrimônio Cultural; Conselho } \\
\text { Municipal de Transporte; Legislação urbanística e ambiental; Legislação municipal de preservação } \\
\text { do patrimônio histórico e cultural; Normas para construção e edificações; Normas para urbanização } \\
\text { e regulamentação fundiária; Plano Diretor participativo; Despesas com melhoria e ampliação do } \\
\text { sistema de transporte; Despesas com direito à cidadania; Despesas com patrimônio cultural e } \\
\text { difusão da cultura; Despesas com gestão ambiental; Despesas com Saneamento Básico Urbano; } \\
\text { Despesas com Habitação Urbana; Despesas com Infraestrutura Urbana; Despesas com } \\
\text { planejamento e orçamento; Secretaria municipal de planejamento urbano; Órgãos de defesa do } \\
\text { consumidor. }\end{array}$ \\
\hline & Meio Ambiente & $\begin{array}{l}\text { Consumo médio de energia elétrica urbana; lluminação pública; Empresas de produção de energias } \\
\text { alternativas; Consumo per capita de água(m3/hab); Aferição do cloro residual na água; Amostras } \\
\text { de cloro residual dentro do padrão de qualidade; Aferição de turbidez na água; Amostras de } \\
\text { turbidez dentro do padrão de qualidade; Aferição de coliformes totais na água; Amostras de } \\
\text { coliformes totais dentro do padrão de qualidade; Esgoto tratado em relação ao coletado; Destino } \\
\text { do lixo; Coleta seletiva do lixo (IBGE); Resíduos sólidos urbanos per capita; Serviços de limpeza } \\
\text { urbana; Áreas de proteção ambiental; Quant. de árvores per capita }\end{array}$ \\
\hline
\end{tabular}




\section{Coleta dos dados secundários dos indicadores escolhidos}

Os dados secundários referentes a cada um dos indicadores foram catalogados a partir da consulta nas bases de dados que disponibilizam informações referentes às cidades brasileiras, dentre as quais o IBGE, Prefeitura Municipal de Natal/RN, Datasus, Anatel, Tribunal Regional Eleitoral, Secretaria do Tesouro Nacional, Ministério das Cidades, Ministério da Cultura.

\section{Normalização dos indicadores}

A necessidade de harmonizar escalas de diferentes vetores de dados relativos à cada indicador pode ser suprida pela normalização dos valores desses vetores. Este processo corresponde, numericamente, à adaptação de escalas, mediante algum processo de mapeamento do espaço de valores originais, para o espaço de valores desejados.

Existem diversos métodos na literatura para normalização de dados, a citar a normalização ou escalonamento min-max, a normalização ou padronização pelo escore-z, normalização ou escalonamento pelo comprimento do vetor, normalização pela média, entre outras. Para esse trabalho, será usada a normalização min-max que mapeia os dados do vetor original X em um novo domínio, definido pelo intervalo [Lmin, Lmax], por meio de transformações lineares, definidas pela função

$$
X^{\prime}=\frac{X-X_{\min }}{X_{\max }-X_{\min }}\left(L_{\max }-L_{\min }\right)+L_{\min },
$$

em que $X=\left\{\left(x_{1}, x_{2}, x_{3}, \ldots, x_{n}\right): x_{i} \in \mathbb{R}, \forall i \in \mathbb{N}\right\}$ é o vetor dos dados a ser normalizado, Xmin e Xmax são, respectivamente, os valores mínimo e máximo do vetor $X$ e $X^{\prime}$ é o vetor de dados normalizados, de mesma dimensão do vetor $X$.

Para a construção do índice intenciona-se mapear todos os conjuntos de dados dos indicadores para o intervalo $[0,1]$. Dessa forma, a equação [1] pode ser reescrita como

$$
X^{\prime}=\frac{X-X_{\min }}{X_{\max }-X_{\min }} \text {. }
$$

A equação acima é válida para indicadores com relação positiva, isto é, variáveis cujo aumento no valor resultará em melhoria no sistema. Nesses casos, o valor 0 será sempre atribuído aos piores valores do indicador, 1 aos melhores. Quando usada com indicadores com relação negativa, isto é, cujo aumento no valor resultará na regressão do sistema avaliado, os valores mapeados terão um efeito invertido, com o valor 0 sendo atribuído aos melhores valores do indicador, 1 aos piores. Para corrigir isso, é necessário trabalhar com o complemento da equação [2].

$$
X^{\prime \prime}=1-\frac{X-X_{\min }}{X_{\max }-X_{\min }}=\frac{X_{\max }-X_{\min }-X+X_{\min }}{X_{\max }-X_{\min }},
$$

ou ainda,

$$
X^{\prime \prime}=\frac{X_{\max }-X}{X_{\max }-X_{\min }} .
$$


Dessa forma, para garantir que, no mapeamento para o intervalo [0, 1], 0 se refira sempre ao pior valor e 1 ao melhor, é preciso utilizar a equação (2) quando o indicador tiver uma relação positiva, e a equação (4), quando for negativa.

\section{Cálculo dos índices por Tema para cada bairro}

O índice de cada Tema é obtido a partir da mediana dos índices dos indicadores que compõe o tema analisado. Assim como a média, a mediana é uma medida de posição, que indica o valor central do conjunto de dados univariados, independente das características de sua distribuição. Isso faz da mediana uma medida mais robusta que a média, isto é, menos sensível à presença de valores discrepantes que, por ventura, possam existir no conjunto analisado, permitindo com que se tenha um valor mais fidedigno e com menos erros de interpretação gerados por algum viés dos dados. De acordo com Bussab et al. (2013), a mediana de um vetor de dados univariados é definida como

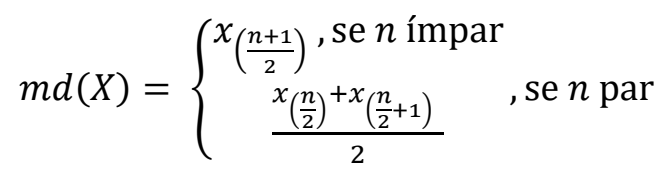

em que $n$ é o número de elementos do vetor de dados.

De modo análogo, calculou-se o índice de cada uma das duas dimensões e o Índice de Vulnerabilidade Socioambiental Urbana da cidade de Natal. Para garantir maior confiabilidade nos índices calculados utilizouse também o cálculo do desvio absoluto mediano (DAM) é uma medida robusta de variabilidade de um conjunto de dados univariados, sendo mais insensível a presença de valores discrepantes do que variância/desvio padrão. Além dessa robustez, o DAM é totalmente imune ao tamanho do conjunto de dados analisados [2]. O DAM é definido como a mediana dos desvios absolutos da mediana dos dados,

$$
D A M=m d(|X-m d(X)|) \text {. }
$$

\section{Representação Gráfica}

O cálculo para transformação dos indicadores em índices permite encontrar um número que varia entre 0 e 1 , onde quanto mais próximo de 1 , melhor se apresenta a cidade em relação às questões que envolvem a vulnerabilidade. Sendo assim, a escala de valores de mínimo e máximo corresponde a 1 (baixa vulnerabilidade ou padrão ideal e 0 (alta vulnerabilidade). Para a representação dos índices referentes a cada indicador definiu-se a representação de cor correspondente ao nível de vulnerabilidade socioambiental urbano.

Quadro 3: Classificação e representação dos índices em níveis de vulnerabilidade socioambiental para cidades brasileiras.

\begin{tabular}{|l|l|l|}
\hline Índice (0 - 1) & Representação de cores & Nível de Vulnerabilidade Socioambiental Urbano \\
\hline $0,0000-0,2500$ & & Muito alto \\
\hline $0,2501-0,5000$ & & Alto \\
\hline $0,5001-0,7500$ & & Baixo \\
\hline $0,7501-1,0000$ & & Muito baixo \\
\hline
\end{tabular}


A definição das cores para cada nível do índice facilitará também a elaboração cartográfica, facilitando a visualização e a leitura dos mapas da cidade. Após delimitado o percurso metodológico utilizado, a sessão seguir apresenta e discute os índices encontrados para cada bairro da cidade de Natal, bem como o índice de vulnerabilidade socioambiental urbano.

\section{RESULTADOS E DISCUSSÃO}

\section{Caracterização da Cidade}

A cidade escolhida para a realização deste estudo foi Natal, capital do estado do Rio Grande do Norte, na região Nordeste do Brasil. Segundo o IBGE (2010) a referida cidade possui uma área territorial de 167,264

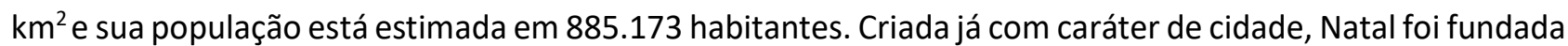
em 25 de dezembro de 1599 (IBGE, 2010). Sua urbanização teve seu início por meio da colonização portuguesa e seu aumento populacional ocorreu de forma lenta. No final do século XIX a cidade possuía apenas 16.050 habitantes (IBGE, 2010).

O investimento de infraestrutura tornou-se mais intenso a partir da década de 1980, onde diversas ações de políticas públicas foram colocadas em prática, como por exemplo, a habitação popular, o investimento na área industrial e investimento no turismo, atividade que se tornou a principal atividade econômica da cidade.

Conforme Costa (2007) o crescimento urbano da cidade, mesmo com as intervenções e os planos urbanísticos, ocorreu segregando o espaço entre as classes de alta renda e as classes de baixa renda. Assim, observa-se que mesmo não sendo áreas homogêneas, pode-se afirmar que nas áreas Norte e Oeste da cidade estabeleceram-se a população mais pobre da cidade, colocando-as em situações de maior vulnerabilidade socioambiental, e as áreas Sul e Leste foram ocupadas pela população mais rica. Desse modo, a cidade possui segregação social e espacial e que não é sua característica exclusiva, mas uma característica das cidades brasileiras.

Atualmente, a cidade de Natal apresenta crescimento vertical, em decorrência de sua região metropolitana se apresentar conturbada, o que impossibilita que se cresça horizontalmente. A espacialização da cidade de Natal pode ser observada na Figura 2 e que segundo dados do IBGE (2010), hoje é composta por 36 bairros subdivididos em quatro regiões administrativas.

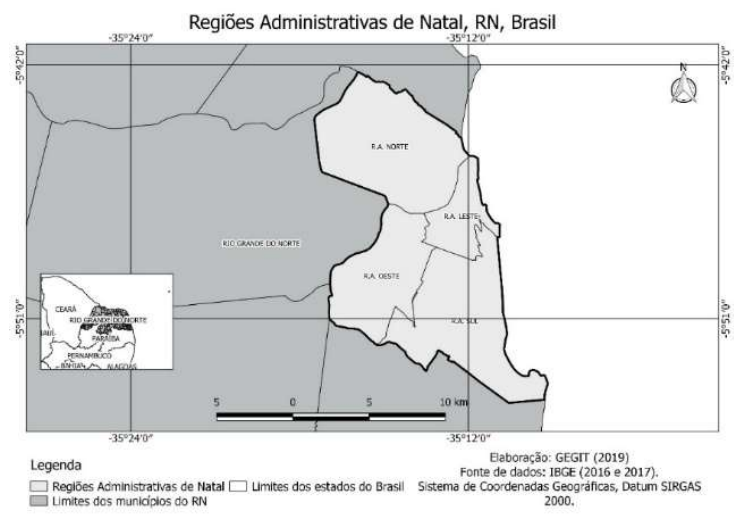

Figura 2: Mapa da cidade de Natal regiões. 
Com base na descrição que aqui foi realizada, desperta o interesse de desenvolver a pesquisa na referida cidade, exatamente para se analisar a vulnerabilidade socioambiental da cidade e oferecer subsídios para que um melhor planejamento ocorra e possa minimizar os impactos ocasionados pelo processo de urbanização.

\section{Escolha dos Indicadores}

Para realização deste estudo, foram escolhidos 72 indicadores para a análise da cidade de Natal $\mathrm{RN}$, conforme quadro 04. A escolha ocorreu preponderantemente em função da disponibilidade de dados para cada indicador, no nível de granularidade por bairros. Deste total, 45 indicadores referem-se a Dimensão Social e 28 indicadores a Dimensão Ambiental.

Duas observações são importantes para a aplicação destes indicadores em Natal: a) Optou-se por excluir o Tema Segurança da análise na Dimensão Social em decorrência da ausência de dados para os indicadores. Dos 09 indicadores que o constituem, apenas o indicador 'Taxa de vítimas de acidentes de trânsito' tinha dados disponíveis por bairros. Por este motivo, para não enviesar os dados, optou-se por sua exclusão; b) A análise do Tema Governança será realizada separadamente e não constituirá o índice, uma vez que os indicadores são categóricos e são medidos pela sua presença/ausência nas cidades. Além disso, diz respeito a análise para cidade e não para bairros como os demais indicadores, pois analisam os órgãos, documentos e regimentos existentes nas cidades.

Quadro 4: Indicadores escolhidos para análise da cidade Natal/RN.

\begin{tabular}{|c|c|c|}
\hline Dimensão & Temas & Indicadores \\
\hline \multirow{4}{*}{ Social } & Saúde & $\begin{array}{l}\text { Profissionais de Saúde por } 1000 \text { Hab.; Taxa de estabelecimentos de saúde; Taxa de unidades de } \\
\text { atenção básica; Taxa de mortalidade infantil; Esperança de vida ao nascer; Taxa de Fertilidade; } \\
\text { Quantidade de casos de dengue. }\end{array}$ \\
\hline & $\begin{array}{l}\text { Educação } \\
\text { Cultura }\end{array}$ & $\begin{array}{l}\text { Taxa de Alfabetização; Taxa de Escolarização; Taxa de escolarização líquida no Ensino Médio; Taxa } \\
\text { de escolarização líquida no Ensino Fundamental; Proporção de jovens de } 15 \text { a } 17 \text { anos sem ensino } \\
\text { fundamental completo; Quantidade de escolas de ensino fundamental e médio na proximidade; } \\
\text { Quantitativo de matrículas escolares; Pessoas consideradas potencialmente ativa (15-59 anos) que } \\
\text { não sabem ler e escrever; População em idade escolar; Taxa de distorção idade-série; Quantidade } \\
\text { de museu na proximidade; Quantidade de biblioteca na proximidade; Quantidade de teatro na } \\
\text { proximidade; Número de estádios e ginásios poliesportivos (ou equipamentos desportivos) }\end{array}$ \\
\hline & Trabalho e renda & $\begin{array}{l}\text { Índice de Gini; Rendimento mensal domiciliar per capita urbano; Rendimento familiar per capita } \\
\text { (\% até } 1 / 2 \mathrm{SM} \text { ); \% de famílias com rendimento de } 10 \text { a } 20 \mathrm{SM} \text {; População (urbana) com rendimento } \\
\text { mensal domiciliar per capita nominal de até } 1 / 4 \text { salário mínimo; Quantidade de pessoas ocupadas } \\
\text { nas empresas do setor informal; Taxa de Ocupação; Taxa de Desemprego; Taxa de Formalidade da } \\
\text { Ocupação; População urbana em extrema pobreza. }\end{array}$ \\
\hline & Moradia & $\begin{array}{l}\text { População em Casa Própria; Quantidade de assentamentos subnormais; População em } \\
\text { aglomerados subnormais; Domicílio com banheiro; Percentual de domicílios servidos por rede de } \\
\text { esgotamento sanitário; Densidade média de moradores por dormitório; Acesso ao sistema de } \\
\text { abastecimento de água; Percentual de domicílios servidos por rede de água; Domicílios com } \\
\text { abastecimento de água; Acesso a serviço de coleta de lixo doméstico; Domicílios com acesso à } \\
\text { rede elétrica; População atendida com frequência de } 2 \text { ou } 3 \text { vezes por semana pelo serviço de } \\
\text { coleta de resíduos; Quantidade de conjunto habitacional de interesse social. }\end{array}$ \\
\hline \multirow[b]{2}{*}{ Ambiental } & $\begin{array}{l}\text { Infraestrutura } \\
\text { Urbana }\end{array}$ & $\begin{array}{l}\text { Taxa de crescimento da população; Densidade demográfica urbana; Quantitativo de praças e/ou } \\
\text { parques; Equipamentos Públicos; Sistema Integrado de Transporte Coletivo; Quantidade de } \\
\text { Acidentes no trânsito. }\end{array}$ \\
\hline & Governança & $\begin{array}{l}\text { Conselho Municipal de segurança pública; Conselho Municipal do Patrimônio Cultural; Conselho } \\
\text { Municipal de Transporte; Legislação urbanística e ambiental; Legislação municipal de preservação } \\
\text { do patrimônio histórico e cultural; Normas para construção e edificações; Normas para } \\
\text { urbanização e regulamentação fundiária; Plano Diretor participativo; Despesas com melhoria e } \\
\text { ampliação do sistema de transporte; Despesas com direito à cidadania; Despesas com patrimônio } \\
\text { cultural e difusão da cultura; Despesas com gestão ambiental; Despesas com Saneamento Básico }\end{array}$ \\
\hline
\end{tabular}




\begin{tabular}{|l|l|l|}
\hline & $\begin{array}{l}\text { Urbano; Despesas com Habitação Urbana; Despesas com Infraestrutura Urbana; Despesas com } \\
\text { planejamento e orçamento; Secretaria municipal de planejamento urbano; Órgãos de defesa do } \\
\text { consumidor. }\end{array}$ \\
\cline { 2 - 3 } & Meio Ambiente & $\begin{array}{l}\text { Consumo per capita de água; Resíduos sólidos urbanos per capita; Serviços de limpeza urbana; } \\
\text { Áreas de proteção ambiental. }\end{array}$ \\
\hline
\end{tabular}

\section{Análise do Índice de Vulnerabilidade Socioambiental Urbano}

Conforme a descrição apresentada no tópico de aspectos metodológicos, para cada um dos 73 indicadores foram coletadas os dados referentes a cada um deles e transformado em índices por meio da normalização. Assim sendo, pode-se encontrar o índice de vulnerabilidade socioambiental urbano para a cidade de Natal (RN), bem como identificar quais os bairros mais e menos vulneráveis da cidade. Para efeito da apresentação dos dados, no Quadro 05 serão apresentados os índices de cada tema e de cada dimensão.

Quadro 5: Índice de vulnerabilidade socioambiental Urbano de Natal/RN.

\begin{tabular}{|c|c|c|c|c|c|c|c|c|}
\hline \multicolumn{9}{|c|}{ Índice de vulnerabilidade socioambiental de Natal/RN } \\
\hline \multirow[b]{2}{*}{ Região Administrativa } & \multirow[b]{2}{*}{ Bairro } & \multicolumn{4}{|c|}{ Social } & \multicolumn{2}{|c|}{ Ambiental } & \multirow[b]{2}{*}{$\begin{array}{c}\text { Índice de } \\
\text { Vulnerabilidade } \\
\text { Socioambiental } \\
\text { por bairros }\end{array}$} \\
\hline & & \begin{tabular}{|c|} 
Índice \\
do \\
Tema \\
Saúde \\
\end{tabular} & \begin{tabular}{|l} 
Índice do \\
Tema \\
Educação \\
e Cultura
\end{tabular} & \begin{tabular}{|c} 
Índice do \\
Tema \\
Trabalho \\
e Renda
\end{tabular} & $\begin{array}{c}\text { Índice } \\
\text { do Tema } \\
\text { Moradia }\end{array}$ & \begin{tabular}{|c|} 
Índice do \\
Tema \\
Infraestrutura \\
Urbana
\end{tabular} & \begin{tabular}{|c|} 
Índice do \\
Tema \\
Meio \\
Ambiente
\end{tabular} & \\
\hline \multirow{12}{*}{ Leste } & Alecrim & 0,3374 & 0,3368 & 0,3563 & 0,5355 & 0,4617 & 0,2837 & 0,3468 \\
\hline & Areia Preta & 0,0648 & 0,2609 & 0,9421 & 0,8746 & 0,1184 & 0,3496 & 0,3052 \\
\hline & Barro Vermelho & 0,1710 & 0,1878 & 0,6944 & 0,9482 & 0,1721 & 0,2952 & 0,2415 \\
\hline & Cidade Alta & 0,0431 & 0,4922 & 0,5225 & 0,6111 & 0,6290 & 0,2217 & 0,5073 \\
\hline & Lagoa Seca & 0,8548 & 0,1769 & 0,6944 & 0,8863 & 0,2807 & 0,1883 & 0,4876 \\
\hline & Mãe Luiza & 0,6230 & 0,2829 & 0,5621 & 0,4802 & 0,0788 & 0,8359 & 0,5211 \\
\hline & \begin{tabular}{|l|} 
Petrópolis \\
\end{tabular} & 0,8217 & 0,4038 & 0,8443 & 0,7348 & 0,3196 & 0,0577 & 0,5693 \\
\hline & \begin{tabular}{|l|} 
Praia do Meio \\
\end{tabular} & 0,0603 & 0,2517 & 0,5009 & 0,6667 & 0,2787 & 0,3107 & 0,2947 \\
\hline & Ribeira & 0,4743 & 0,3723 & 0,4624 & 0,4394 & 0,4123 & 0,5155 & 0,4509 \\
\hline & Rocas & 0,4141 & 0,2278 & 0,6183 & 0,8484 & 0,4024 & 0,2691 & 0,4082 \\
\hline & \begin{tabular}{|l|} 
Santos Reis \\
\end{tabular} & 0,4737 & 0,1946 & 0,4369 & 0,5143 & 0,4914 & 0,8795 & 0,4825 \\
\hline & Tirol & 0,9857 & 0,4674 & 1,0000 & 0,9060 & 0,4214 & 0,5189 & 0,7125 \\
\hline \multirow{7}{*}{ Norte } & Igapó & 0,3056 & 0,2688 & 0,3895 & 0,7657 & 0,1741 & 0,9730 & 0,3475 \\
\hline & Lagoa Azul & 0,0855 & 0,4537 & 0,2279 & 0,6667 & 0,4019 & 0,9116 & 0,4278 \\
\hline & N. Sra da Apresentação & 0,2439 & 0,3749 & 0,2737 & 0,5385 & 0,1909 & 0,8076 & 0,3243 \\
\hline & Pajuçara & 0,1352 & 0,3377 & 0,2279 & 0,7666 & 0,2796 & 0,9542 & 0,3087 \\
\hline & Potengi & 0,5635 & 0,6417 & 0,5827 & 0,8619 & 0,6044 & 0,9692 & 0,6231 \\
\hline & Redinha & 0,1554 & 0,1510 & 0,1744 & 0,3846 & 0,2444 & 0,9310 & 0,2094 \\
\hline & Salinas & 0,0000 & 0,0000 & 0,0000 & 0,2995 & 0,0000 & 0,7452 & 0,0000 \\
\hline \multirow{10}{*}{ Oeste } & Bom Pastor & 0,1651 & 0,1348 & 0,3302 & 0,4041 & 0,4092 & 0,8584 & 0,3671 \\
\hline & Cidade Nova & 0,0353 & 0,0744 & 0,2395 & 0,2131 & 0,2284 & 0,9025 & 0,2207 \\
\hline & Cidade da Esperança & 0,2500 & 0,2503 & 0,7705 & 0,9423 & 0,2943 & 0,7701 & 0,5322 \\
\hline & Dix-Sept Rosado & 0,1389 & 0,2950 & 0,4989 & 0,6830 & 0,0486 & 0,7600 & 0,3970 \\
\hline & Felipe Camarão & 0,4589 & 0,4180 & 0,4644 & 0,6106 & 0,3807 & 0,9225 & 0,4617 \\
\hline & Guarapes & 0,1583 & 0,1167 & 0,2014 & 0,3077 & 0,2511 & 0,9328 & 0,2262 \\
\hline & Nordeste & 0,0556 & 0,1843 & 0,3648 & 0,6667 & 0,4240 & 0,8155 & 0,3944 \\
\hline & $\begin{array}{l}\text { Nossa Senhora de } \\
\text { Nazaré }\end{array}$ & 0,2588 & 0,2815 & 0,6712 & 0,8402 & 0,1716 & 0,8011 & 0,4763 \\
\hline & \begin{tabular}{|l|} 
Planalto \\
\end{tabular} & 0,2684 & 0,1702 & 0,3044 & 0,5581 & 0,1076 & 0,9001 & 0,2864 \\
\hline & Quintas & 0,4400 & 0,3052 & 0,3473 & 0,8333 & 0,3333 & 0,9351 & 0,3937 \\
\hline \multirow{7}{*}{ Sul } & Candelária & 0,3379 & 0,1336 & 0,9226 & 0,5342 & 0,4222 & 0,7252 & 0,4782 \\
\hline & Capim Macio & 0,1774 & 0,2651 & 0,9108 & 0,6923 & 0,4214 & 0,6670 & 0,5442 \\
\hline & Lagoa Nova & 0,1736 & 0,6657 & 0,7750 & 0,7594 & 0,5740 & 0,2231 & 0,6199 \\
\hline & \begin{tabular}{|l|} 
Neópolis \\
\end{tabular} & \begin{tabular}{|l|}
0,3718 \\
\end{tabular} & 0,3253 & 0,8372 & 0,9022 & 0,6426 & 0,7115 & 0,6770 \\
\hline & Nova Descoberta & 0,3472 & 0,2794 & 0,6394 & 0,7588 & 0,2916 & 0,8018 & 0,4933 \\
\hline & Pitimbu & 0,3335 & 0,3361 & 0,7408 & 0,9767 & 0,3659 & 0,7100 & 0,5379 \\
\hline & Ponta Negra & 0,1692 & 0,3433 & 0,5583 & \begin{tabular}{|l|}
0,7798 \\
\end{tabular} & 0,4796 & 0,6140 & 0,5190 \\
\hline \multicolumn{2}{|l|}{ Índice dos Temas } & 0,2544 & \begin{tabular}{|l|}
0,2804 \\
\end{tabular} & 0,5117 & 0,6877 & 0,3264 & 0,7650 & \\
\hline \multicolumn{2}{|l|}{ Índice da Dimensão } & \multicolumn{4}{|l|}{0,3961} & \multirow{2}{*}{\multicolumn{2}{|c|}{0,5457}} & \\
\hline \multicolumn{2}{|c|}{ Índice de vulnerabilidade socioambiental de Natal } & \multicolumn{4}{|l|}{0,4709} & & & \\
\hline
\end{tabular}

Os índices dos temas foram gerados a partir do cálculo da mediana dos indicadores por bairro que é constituído cada tema. O mesmo procedimento foi utilizado para o cálculo das dimensões e do índice de 
vulnerabilidade socioambiental de Natal. Para analisar cada índice se tomará como base os intervalos numéricos do índice (Quadro 5) e a escala de cores (Quadro 3) para classificar o nível de vulnerabilidade socioambiental urbana dos bairros, bem como da cidade de Natal como um todo.

A Dimensão Social está relacionada como o nível de qualidade de vida da população, com a satisfação das necessidades humanas, à justiça social, ao nível de educação e às condições básicas à sobrevivência humana. Ademais, evidencia o desempenho macroeconômico como também procura expor a identidade cultural, corroborando as evidências de uma população que tenha acesso à educação, cultura, esporte e lazer e que possa, por intermédio disso, aumentar sua capacidade intelectual e conhecimento acerca de si próprio e do espaço que a envolve, contribuindo para uma cidade mais justa e igualitária.

O Tema Saúde apresenta-se com o índice de 0,2544 e é classificado com o nível 'Alto' para a vulnerabilidade socioambiental. Dos 36 bairros existentes na cidade, 16 (Areia Preta, Barro Vermelho, Cidade Alta, Praia do Meio, Lagoa Azul, Nossa Senhora da Apresentação, Pajuçara, Redinha, Salinas, Bom Pastor, Cidade Nova, Dix-Sept Rosado, Guarapes, Capim Macio, Lagoa Nova, Ponta Negra) se apresentaram com o nível de vulnerabilidade socioambiental classificado como 'Muito Alto'. Os bairros destacados contemplam as 04 regiões administrativas, evidenciando que as questões referentes a saúde constituem um gargalo na cidade como um todo.

Apenas três bairros (Lagoa Seca, Petrópolis, Tirol) apresentaram índices que se classificam com 'muito baixo'. Todos localizados na região Leste da cidade. No que se refere aos indicadores deste tema, destacam-se os que se classificaram como o nível 'muito alto' de vulnerabilidade socioambiental, quais sejam: Profissionais de Saúde por 1000 Hab.; Taxa de estabelecimentos de saúde; Taxa de unidades de atenção básica e Quantidade de casos de dengue. Os três primeiros indicadores apontados estão diretamente ligados à disponibilidade de atendimentos básicos de saúde à população, explicitando a sua precariedade quanto à oferta desses serviços que estão bem aquém da necessidade da população de cada bairro. $\mathrm{O}$ indicador que analisa o quantitativo de casos de dengue que também foi classificado como 'muito alto', caracteriza um sério problema de saúde pública na cidade, que além de sofrer interferência das condições do meio ambiente que favorecem a proliferação do vetor, está também relacionado com fatores sociais, econômicos e políticos que envolve as pessoas que habitam na cidade.

O Tema Educação e Cultura apresentou um índice de 0,2804, classificando-o como 'Alto'. Doze bairros (Barro Vermelho, Lagoa Seca, Rocas, Santos Reis, Redinha, Salinas, Bom Pastor, Cidade Nova, Guarapes, Nordeste, Planalto, Candelária) apresentaram índices classificados como 'Muito alto', evidenciando o quão vulneráveis são os indicadores de Educação e Cultura em Natal, sobretudo na região Oeste que apresenta $50 \%$ dos seus bairros com um nível de vulnerabilidade socioambiental classificado como 'Muito alto'. É importante destacar que dos 36 bairros de Natal, nenhum apresentou um índice satisfatório que os classificassem como 'muito baixo'.

Os indicadores que se destacam como os que possuem um nível 'muito alto' de vulnerabilidade estão: Quantidade de escolas de ensino fundamental e médio na proximidade; Quantitativo de matrículas escolares; População em idade escolar; Quantidade de museu; Quantidade de biblioteca; Quantidade de 
teatro; Número de estádios e ginásios poliesportivos. Todos estes indicadores estão diretamente relacionados com o acesso e a qualidade do ensino básico para crianças, adolescentes e jovens, e o direcionamento adequado para que possam ter uma melhor perspectiva de futuro com melhores condições de trabalho, renda e melhor qualidade de vida.

O Tema Trabalho e Renda apresentou o índice de 0,5177 e foi classificado com o ‘Baixo' nível de vulnerabilidade socioambiental urbana. Do total de bairros, apenas seis (Lagoa Azul, Pajuçara, Redinha, Salinas, Cidade Nova, Guarapes) apresentam índices que os classificam com um nível 'alto' para a vulnerabilidade socioambiental e nove (Areia Preta, Petrópolis, Tirol, Cidade da Esperança, Candelária, Lagoa Nova, Neópolis, Pitimbu) apresentam índices que os classificam com nível 'muito baixo'.

Os indicadores que mais se destacam com um nível 'muito alto' para a vulnerabilidade, refere-se ao Percentual de famílias que tem rendimento entre 10 a 20 salários mínimos e Rendimento mensal domiciliar per capita. Ambos indicadores podem ser considerados diametralmente opostos e por se apresentarem com um nível tão negativo, implica dizer que há concentração de renda na cidade de Natal, cenário este que configura a realidade brasileira.

O Tema Moradia apresentou um índice de $\mathbf{0 , 6 8 7 7}$ sendo classificado como 'Baixo'. É importante observar que apenas um bairro (Cidade Nova) se classificou como 'Muito alto' e cinco bairros (Salinas, Guarapes, Redinha, Bom Pastor, Mãe Luiza) se apresentaram com índice que os classificam como 'Alto'. Tal fato denota que em função dos indicadores analisados, a cidade de Natal apresenta poucos bairros com problemas referentes a moradia.

Os indicadores População em Casa Própria; Acesso ao sistema de abastecimento de água; Domicílios com abastecimento de água, foram os três indicadores que se apresentaram com os índices mais baixos, demonstrando dessa forma que uma parcela significativa da população natalense não possui condições de adquirir sua casa própria. Ademais, os outros dois indicadores estão diretamente ligados com o acesso à água de qualidade, tanto relativo ao acesso ao abastecimento de água que envolve indústria, comércio, bem como analisa os domicílios que tem acesso ao abastecimento de água. É importante destacar que a água é um recurso vital ao ser humano e reflete nas condições de saúde e higiene. Assim sendo, se verifica a urgência de se estabelecer políticas direcionadas que visem melhorar o sistema de abastecimento de água, para que este recurso chegue de forma adequada à população, uma vez que de acordo com a Legislação Brasileira, toda a água fornecida à população por rede de abastecimento geral tem de ser tratada e apresentar qualidade adequada para o consumo.

O Decreto no 5.440, de 4 de maio de 2005 estabelece definições e procedimentos sobre o controle de qualidade da água de sistemas de abastecimento e institui mecanismos e instrumentos para divulgação de informação ao consumidor sobre a qualidade da água para consumo humano. Em seu Art. $3^{\circ}$ define: "Toda água destinada ao consumo humano, distribuída coletivamente por meio de sistema ou solução alternativa coletiva de abastecimento de água, deve ser objeto de controle e vigilância da qualidade da água."

A Dimensão Social apresentou um índice de 0,3961 que o classifica como 'Alto' nível de vulnerabilidade socioambiental representando uma situação indesejável para a cidade quanto as questões 
sociais analisadas. Dentre os temas que compõem esta dimensão, dois (Saúde e Educação e Cultura) foram classificados com o nível 'alto' para a vulnerabilidade socioambiental, apontando a necessidade do desenvolvimento de planejamento e de políticas públicas que envolvam essas temáticas, de modo a modificar esse cenário e proporcionar para a população o acesso aos serviços de saúde, a educação, a cultura, ao esporte e lazer e que possam, por intermédio disso, aumentarem sua capacidade intelectual e o conhecimento acerca de si próprio e do espaço que a envolve, contribuindo para uma cidade mais justa e igualitária.

A Dimensão Ambiental corresponde aos aspectos relacionados ao uso dos recursos naturais, à degradação do ambiente, aos objetivos de preservação e conservação do meio ambiente, aspectos considerados fundamentais para manter a qualidade de vida e ambiental das atuais e futuras gerações.

O Tema Infraestrutura Urbana apresentou um índice de 0,3264 que o classifica com um nível 'Alto' para a vulnerabilidade socioambiental. Dos 36 bairros, 11 apresentaram índices que os classificam como 'Muito alto' para a vulnerabilidade socioambiental e nenhum bairro apresentou um índice que os classificasse como 'Baixo' ou 'Muito baixo' nível de vulnerabilidade socioambiental.

Os indicadores que mais se destacam por terem apresentados índices classificados como 'muito alto' e que contribuíram para que o nível desse tema fosse considerado alto foram: Quantitativo de praças e/ou parques; Equipamentos Públicos; Sistema Integrado de Transporte Coletivo. Estes indicadores explicitam variáveis que possibilita a população ter uma melhor qualidade de vida na cidade que moram. As praças e parques possibilita a ida das pessoas às ruas tornando-as vivas e mais movimentadas, os passeios em locais públicos, a integração da população com a cidade, tornando-as pertencentes ao ambiente em que as circundam.

Os equipamentos públicos, segundo a NBR 9284 refere-se aos bens públicos ou privados, de utilidade pública, destinados à prestação de serviços necessários ao funcionamento da cidade. Segundo a Lei Federal 6.766/79, consideram-se, urbanos, os equipamentos públicos de abastecimento de água, serviços de esgotos, energia elétrica, coleta de águas pluviais, rede telefônica e gás canalizado. Para os bairros de Natal, este indicador também se apresentou com um nível 'muito alto' para a vulnerabilidade socioambiental.

O indicador Sistema Integrado de Transporte Coletivo tem por definição o conjunto de medidas de natureza físico-operacional, tarifária e institucional destinadas a articular e racionalizar os serviços de transporte público. Em Natal, o sistema de transporte intramodal do tipo ônibus - ônibus é a principal existente. Este indicador possibilita a facilidade de mobilidade dos usuários, facilitando uma redução de despesas e de tempo para se locomover dentro de sua cidade e entre bairro-centro (e centro-bairro). $\mathrm{O}$ fato de ter tido um índice considerado 'muito alto' para o nível de vulnerabilidade socioambiental, reflete a necessidade de revisão nas ações que envolvem os transportes públicos na cidade de Natal, possibilitando assim, que a mobilidade urbana seja um fator positivo e contribua para melhores índices de infraestrutura urbana na cidade de Natal. 
O Tema Meio Ambiente apresentou o índice de $\mathbf{0 , 7 6 5 0}$ considerado como um nível 'Muito baixo' para a vulnerabilidade socioambiental urbana. Apenas quatro bairros (Cidade Alta, Lagoa Seca, Petrópolis, Lagoa Nova) se apresentaram com índices que se classificam em um nível de 'Muito alto' para a vulnerabilidade socioambiental e 18 bairros apresentaram-se com um índice que se classifica em 'muito baixo', demonstrando condições adequadas sob a perspectiva dos indicadores que este tema foi analisado.

O indicador analisado mais negativamente foi Resíduos sólidos urbanos per capita que ficou em uma zona limítrofe mais baixo do índice, demonstrando a necessidade de que as pessoas possam rever seus hábitos de consumo e de estilo de vida, de modo a minimizar o volume de resíduos gerados todos os dias na cidade. É importante ressaltar que na análise deste indicador não se inclui o percentual de resíduos gerados pelo comércio e pela indústria, o que certamente leva ao entendimento que também se apresentaria com um índice considerado 'muito alto' para a vulnerabilidade socioambiental.

Para o Tema Governança, conforme as explicações dadas nos aspectos metodológicos deste artigo, a análise deste tema não compôs o índice por ser composto de indicadores categóricos. Desse modo, identificou-se a existência dos indicadores (Quadro 04) na cidade de Natal, apresentando-se positivamente e, para efeito de análise, se atribuiu um índice de 1,00 que o classifica como 'Muito baixo' para a vulnerabilidade socioambiental urbana. Este tema envolve indicadores que analisa a forma como o Estado gerencia seus recursos e ações legitimando os direitos da população, garantindo a capacidade e a mobilização necessárias para a consolidação de um ambiente saudável para todos. Ademais, também é analisado por meio da análise da infraestrutura para alguns instrumentos necessários ao bom andamento de uma sociedade que quando da sua existência, promovem o sentimento de pertencimento e de inclusão das pessoas e os direciona para um desenvolvimento que seja sustentável. Para este tema foram analisados a existência de documentos, conselhos, legislação municipal, normas e despesas utilizadas e destinadas a resolver a questões acima mencionadas para a cidade de Natal. Por se tratar de variáveis que analisam a cidade e as normas e regulamentos e se aplicarem para a cidade, não foi possível separar a sua existência ou execução por bairros.

A Dimensão Ambiental obteve um índice de 0,5457 o que o classifica com um nível considerado 'baixo' para a vulnerabilidade socioambiental urbana. O tema Infraestrutura Urbana apresentou-se classificado negativamente, despertando a necessidade de ações de melhorias nos aspectos que interferem na qualidade da infraestrutura urbana. Para tanto, é preciso verificar individualmente os indicadores que o constituem de modo que se possa estabelecer ações que possibilitem a sua melhoria de forma contínua. 0 conjunto de informações produzidas por esses índices ambientais oferece subsídios para compreender aspectos relevantes do processo de degradação ambiental ocasionados pela falta de infraestrutura, comportamentos e hábitos inadequados, formas de agir e pensar da população, com o objetivo de compreender e respeitar as limitações dos recursos naturais e o tempo necessário para que o meio ambiente possa se restabelecer.

A partir do índice e da classificação dos níveis de vulnerabilidade socioambiental por bairro, foi possível elaborar o produto cartográfico, como forma de melhor visualizar a situação da cidade de Natal/RN. 
Conforme apresentado nos índices e visualizado claramente na Figura 03, foi possível identificar o nível de vulnerabilidade socioambiental para a cidade de Natal de $\mathbf{0 , 4 7 0 9}$, considerada como 'Alto'. Esse resultado é considerado preocupante, exigindo uma postura mais ativa do poder público na resolução dos problemas que colocam a população em uma situação de vulnerabilidade socioambiental.

Dos 36 bairros, 25 se encontram em situação que os classificam com um nível 'Alto' ou 'Muito Alto' para a vulnerabilidade socioambiental, o que explicita que a cidade apresenta maiores fragilidades nas questões sociais, principalmente de moradia, de educação e cultura, de emprego e renda e na disparidade existente frente as questões de infraestrutura urbana. Por esse motivo, ressalta-se a importância de que se analise a cidade com um olhar mais direcionado para cada tema e cada indicador analisado e se identifique quais deles necessitam de mais atenção para sanar as problemáticas que os envolvem.

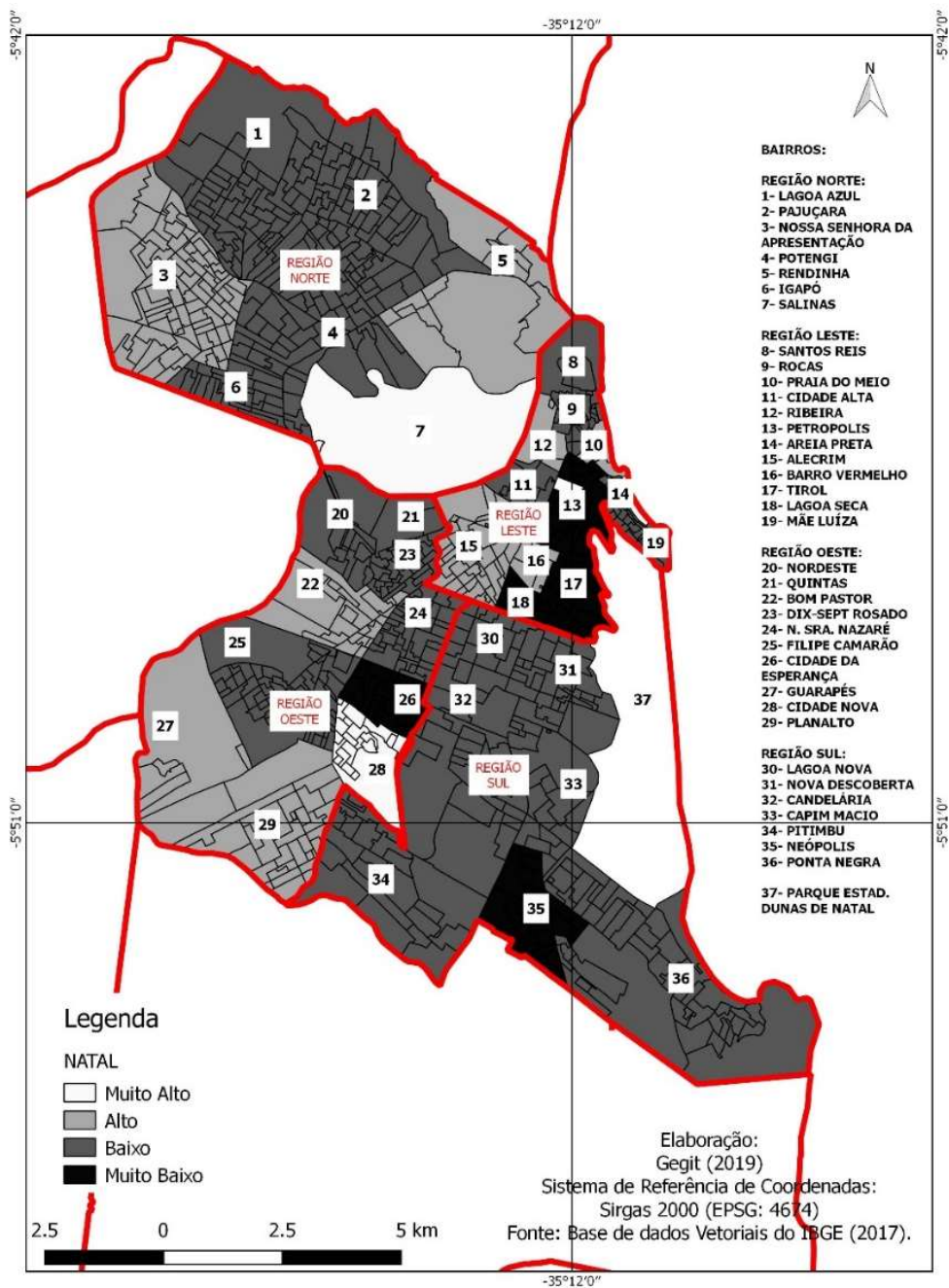

Figura 3: Mapa da vulnerabilidade socioambiental da cidade de Natal/RN por bairros.

\section{CONCLUSÕES}

A importância de se analisar a vulnerabilidade socioambiental da cidade de Natal/RN a partir do conjunto de indicadores que enfatiza as questões sociais e ambientais que caracterizam o cenário urbano brasileiro, se consolida na compreensão das questões sociais, econômicas e urbanísticas reveladas por meio 
dos indicadores analisados, ao passo que revela uma certa invisibilidade de uma parcela da população, principalmente, quanto à negação de seus direitos.

Natal é uma cidade de porte médio e está situada em um lugar privilegiado do Brasil a qual se confere uma qualidade de vida superior, principalmente nas diversas formas de divulgação da cidade para se atrair turistas e investidores. Imagem está, revelada em decorrência, principalmente, de seu patrimônio natural. No entanto, a Natal vivida pelos seus citadinos revela um quadro de problemas iminentes comprometendo a sua imagem da cidade bela e agradável para se morar.

Como observado, o nível de vulnerabilidade socioambiental para a cidade de Natal foi de 0,4709, considerado como 'Alto'. Esse resultado é considerado insatisfatório e preocupante, pois coloca a cidade frente a muitas problemáticas que demandam urgência como forma de garantir condições mínimas de qualidade de vida aos seus citadinos. Ademais, é importante destacar a necessidade de analisar a cidade com um olhar mais direcionado para cada região e para cada bairro, pois cada um apresentam especificidades que os colocam em divergência em vários aspectos, mesmo quando exibem as mesmas problemáticas.

Esta percepção é endossada pela reflexão feita por Kowarick (2000) que chama atenção ao pontuar que os principais investimentos públicos são comumente realizados em áreas onde vivem e trabalham os grupos com renda média e alta, e que os investimentos públicos em bens de consumo coletivo, têm sido tradicionalmente realizados com prejuízo para a grande massa de trabalhadores. São estas ações por parte do Estado que privilegiam uma parcela da população e segrega a outra parcela que tem o direito à cidade negado.

Os indicadores que obtiveram um nível alto ou muito alto para a vulnerabilidade, foram identificados nos bairros mais periféricos e mais pobres, em áreas com más condições urbanísticas e sanitárias, denotando uma concentração de indicadores avaliados negativamente e revelando uma cidade que não é vista pelos turistas e pelos moradores das regiões mais abastadas.

Com base nestas discussões, este estudo constitui importante instrumento que estabelece uma relação entre o ambiente acadêmico e a sociedade civil, viabilizando o debate entre tais partes e, por conseguinte, possibilitando a estruturação de planos de desenvolvimento pautados na construção de uma sociedade justa e equitativa.

\section{REFERÊNCIAS}

ALVES, H. P.; ALVES, C. D.; PEREIRA, M. N.; MONTEIRO, A. M. V.. Dinâmicas de urbanização na hiperperiferia da metrópole de São Paulo: análise dos processos de expansão urbana e das situações de vulnerabilidade socioambiental em escala intraurbana. Revista Brasileira de estudos populacionais, Rio de Janeiro, v.7, n.1, p.141-159, 2010.

ALVES, H. P. F.. Vulnerabilidade socioambiental na metrópole paulistana: uma análise sociodemográfica das situações de sobreposição espacial de problemas e riscos sociais e ambientais. Revista Brasileira de Estudos de População, São Paulo, v.23, n.1, p.43-59, 2006.
ARAÚJO, M. C. C.; CÂNDIDO, G. A.. Qualidade de vida e sustentabilidade urbana. Revista HOLOS, v.1, n.30, 2014.

BRAGA, T. M.. Sustentabilidade e condições de vida em áreas urbanas: medidas e determinantes em duas regiões metropolitanas brasileiras. Revista Eure, Santiago, v.32, n.96, p.47-71, 2006.

BRAGA, T. M.; FREITAS, A. G.; DUARTE, G. S.. Índice de Sustentabilidade Urbana. In: ENCONTRO DA ASSOCIAÇÃO NACIONAL DE PÓS-GRADUAÇÃO E PESQUISA EM AMBIENTE E SOCIEDADE, 1. Anais. São Paulo: AMPAS, 2002. 
BUSSAB, W. O.; MORETIN, P. A.. Estatística Básica. 8 ed. São Paulo: Saraiva, 2013

COSTA, A. A.. A verticalização de Natal: elemento de impactos socioambientais sobre o seu desenvolvimento urbano. In: NUNES, E. et al. Dinâmica e gestão do território potiguar. Natal: EDUFRN, 2007. p.267-283.

CUTTER, S. L.. A ciência da vulnerabilidade: modelos, métodos e indicadores. Revista Crítica de Ciências Sociais, v.93, n.1, p.59-70, 2011.

CUTTER, S. L.. Vulnerability to environmental hazards. Progress in human geography, v.20, n.4, p.529-539, 2003.

FIGUEIREDO, A. S.. Índice de qualidade de vida urbana de Campo Grande/MS. PLANURB, 2008.

FLORISSI, E.. Desenvolvimento Urbano Sustentável: um estudo sobre sistemas de indicadores de sustentabilidade urbana. Dissertação (Mestrado) - Universidade Federal de Pernambuco, Recife, 2009.

GEHL, J.. Cidades para pessoas. Perspectiva, 2015.

GOMES, L. M. S.; GOMES, A. O.. Desenvolvimento e Análise de um Índice de Qualidade de Vida Urbana. In: Congresso Brasileiro de Gestão Ambiental, 8. Anais. Campo Grande, 2017.

HERCULANO, S.. A qualidade de vida e seus indicadores. Ambiente \& Sociedade., v.1, n.2, 2000.

IBGE. Instituto Brasileiro de Geografia e Estatística. Censo Demográfico. Rio de Janeiro: IBGE, 2010.

JACOBS, J.. Morte e vida de grandes cidades. 3 ed. São Paulo: WMF Martins, 2011.

KOWARICK, L.. Escritos Urbanos. São Paulo: 34, 2000.

KOWARICK, L.. Viver em risco: Sobre a vulnerabilidade socioeconômica e civil. São Paulo: 34, 2009.

KUHLICKE, C.; SCOLOBIG, A.; TAPSELL, S.; STEINFÜHRER, A.; MARCHI, B.. Contextualizing Social Vulnerability: Findings from case studies across Europe. Natural Hazards, v.58, n.2, p.789-810, 2011.

MACHADO, L.. Índice de Mobilidade Sustentável para avaliar a qualidade de vida urbana: Estudo de caso: Região Metropolitana de Porto Alegre: RMPA. Dissertação (Mestrado m Planejamento Urbano e Regional) Universidade Federal do Rio Grande do Sul, Porto Alegre, 2010.

MAIOR, M. M. S.. Vulnerabilidade socioambiental e expansão urbana: uma proposta metodológica para análise da cidade de João Pessoa/PB. Tese (Doutorado em Recursos Naturais) - Universidade Federal de Campina Grande, Campina Grande, 2014.
MARICATO, E.. 0 impasse da política urbana no Brasil. 3 ed. Petrópolis: Vozes, 2014

MARTINS, M. F.; CÂNDIDO, G. A.. Modelo de avaliação do nível de sustentabilidade urbana: proposta para as cidades brasileiras. Revista Brasileira de Gestão Urbana, v.7, n.3, p.397-410, 2015

MORATO, R. G.. Análise Espacial e Desigualdade Ambiental no Município de São Paulo. Tese (Doutorado em Geografia Humana) - Universidade de São Paulo, 2008.

NAHAS, M. I. P.. Bases teóricas, metodologia de elaboração e aplicabilidade de indicadores intra-urbanos na gestão municipal da qualidade de vida urbana em grandes cidades: o caso de Belo Horizonte. Tese (Doutorado de Ecologia e Recursos Naturais) - Universidade Federal de São Carlos, 2002.

PEREIRA, F. S.; VIEIRA, I. C. G.. Expansão urbana da Região Metropolitana de Belém sob a ótica de um sistema de índices de sustentabilidade. Revista Ambiente e Água, v.11, n.3, 2016

PESSOA, Z. S.. A Metrópole periférica: identidade e vulnerabilidade socioambiental na Região Metropolitana de Natal-RN/Brasil. Tese (Doutorado) - Universidade Estadual de Campinas, Campinas, 2012.

RIBEIRO, R. J. C.. Índice Composto de Qualidade de Vida Urbana: Aspectos de Configuração Espacial, Socioeconômicos e Ambientais Urbanos. Tese (Doutorado em Arquitetura e Urbanismo) - Universidade de Brasília, 2008.

ROGERS, R.. Cidades para um pequeno planeta. São Paulo: Gustavo Gili, 2015.

ROGGERO, M. A.. Qualidade de vida urbana nas bordas da metrópole: centralidades e periferias. Tese (Doutorado em Geografia Física) - Universidade de São Paulo, São Paulo, 2015.

ROLNIK, R.. Guerra dos Lugares: a colonização da terra e da moradia na era das finanças. São Paulo: Boitempo, 2015.

ROSSETTO, A. M.. Proposta de um Sistema integrado de Gestão do Ambiente Urbano (SIGAU) para o desenvolvimento sustentável de cidades. Tese (Doutorado em Engenharia de Produção) - Universidade Federal de Santa Catarina, Florianópolis, 2003.

SOUZA, J.. Ralé brasileira: quem é e como vive. Belo Horizonte: UFMG, 2009.

SPOSATI, A.. Mapa da exclusão/inclusão social da cidade de São Paulo: 2000: Dinâmica social dos anos 90. 2000.

VEIGA, A. J. P.. Sustentabilidade urbana, avaliação e indicadores: um estudo de caso sobre Vitória da Conquista/BA. Tese (Doutorado) - Universidade Federal da Bahia, Salvador, 2010.

A CBPC - Companhia Brasileira de Produção Científica (CNPJ: 11.221.422/0001-03) detém os direitos materiais desta publicação. Os direitos referem-se à publicação do trabalho em qualquer parte do mundo, incluindo os direitos às renovações, expansões e disseminações da contribuição, bem como outros direitos subsidiários. Todos os trabalhos publicados eletronicamente poderão posteriormente ser publicados em coletâneas impressas sob coordenação da Sustenere Publishing, da Companhia Brasileira de Produção Científica e seus parceiros autorizados. Os (as) autores (as) preservam os direitos autorais, mas não têm permissão para a publicação da contribuição em outro meio, impresso ou digital, em português ou em tradução. 